\title{
Adverse events among patients registered in high-acuity areas of the emergency department: a prospective cohort study
}

\author{
Lisa Anne Calder, MD, MSc; ${ }^{*}$ Alan Forster, MD, MSc; ${ }^{\dagger}$ Melanie Nelson, RN; ${ }^{*}$ Jason Leclair, MD; ${ }^{*}$ \\ Jeffrey Perry, MD, MSc; ${ }^{*}$ Christian Vaillancourt, MD, MSc; ${ }^{*}$ Guy Hebert, MD; ${ }^{*}$ A. Adam Cwinn, MD; \\ George Wells, PhD; ${ }^{\ddagger}$ lan Stiell, MD, MSc ${ }^{*}$
}

\section{ABSTRACT}

Objective: To enhance patient safety, it is important to understand the frequency and causes of adverse events (defined as unintended injuries related to health care management). We performed this study to describe the types and risk of adverse events in high-acuity areas of the emergency department (ED).

Methods: This prospective cohort study examined the outcomes of consecutive patients who received treatment at 2 tertiary care EDs. For discharged patients, we conducted a structured telephone interview 14 days after their initial visit; for admitted patients, we reviewed the inpatient charts. Three emergency physicians independently adjudicated flagged outcomes (e.g., death, return visits to the ED) to determine whether an adverse event had occurred.

Results: We enrolled 503 patients; one-half $(n=254)$ were female and the median age was 57 (range 18-98) years. The majority of patients ( $n=369,73.3 \%$ ) were discharged home. The most common presenting complaints were chest pain, generalized weakness and abdominal pain. Of the 107 patients with flagged outcomes, 43 (8.5\%, 95\% confidence interval $8.1 \%-8.9 \%$ ) were considered to have had an adverse event through our peer review process, and over half of these $(24,55.8 \%)$ were considered preventable. The most common types of adverse events were as follows: management issues ( $n=18,41.9 \%$ ), procedural complications ( $n=$ $13,30.2 \%)$ and diagnostic issues ( $n=10,23.3 \%)$. The clinical consequences of these adverse events ranged from minor (urinary tract infection) to serious (delayed diagnosis of aortic dissection).

Conclusion: We detected a higher proportion of preventable adverse events compared with previous inpatient studies and suggest confirmation of these results is warranted among a wider selection of EDs.

Keywords: adverse events, patient safety, emergency medicine

\section{RÉSUMÉ}

Objectif : Pour améliorer la sécurité des patients, il est important de comprendre la fréquence et les causes des événements indésirables (EI) (définis comme des blessures ou complications non intentionnelles liées à la gestion des soins de santé). Nous avons effectué cette étude pour décrire les types et risques d'El de secteurs de soins très intensifs de services d'urgence.

Méthodes : Dans cette étude de cohorte prospective, nous avons examiné les résultats de patients vus consécutivement ayant été traités à deux urgences d'hôpitaux de soins tertiaires. Nous avons interviewé par téléphone 14 jours après leur visite initiale les patients ayant reçu leur congé et examiné le dossier médical des patients hospitalisés. Trois médecins d'urgence ont statué indépendamment sur les résultats marqués ( $p$. ex., décès, retours à l'urgence) pour déterminer si un événement indésirable était survenu ou non. Résultats : Nous avons recruté 503 patients; la moitié $(n=254)$ était des femmes et l'âge médian était de 57 ans (fourchette de 18 à 98 ans). La majorité des patients ( $n=369,73,3 \%$ ) ont obtenu leur congé. Les douleurs thoraciques, une faiblesse généralisée et des douleurs abdominales étaient les raisons de consultation les plus fréquentes. Parmi les 107 patients qui avaient des résultats marqués, notre processus d'examen par les pairs a permis de déterminer que $43(8,5 \%$, intervalle de confiance à $95 \%$, de 8,1 à 8,9\%) avaient subi un $\mathrm{El}$, et pour plus de la moitié de ces patients $(24,55,8 \%)$, ces El étaient considérés comme évitables. Les types les plus communs d'El étaient les suivants : questions de gestion ( $n=18,41,9 \%$ ), complications suite à une intervention $(n=13,30,2 \%)$ et problèmes liés au diagnostic ( $n=10,23,3 \%$ ). Les conséquences cliniques de ces El variaient, allant de mineures (infection urinaire) à graves (diagnostic retardé de dissection aortique).

Conclusion : Nous avons détecté une plus forte proportion d'El évitables par rapport à des études antérieures de patients hospitalisés, ce qui justifie des études plus poussées auprès d'un plus grand échantillon de services d'urgence pour confirmer ces résultats.

From the Departments of *Emergency Medicine, IInternal Medicine and ¥Clinical Epidemiology, University of Ottawa, Ottawa, Ont.

Submitted May 1, 2009; Revised Oct. 20, 2009; Accepted Oct. 23, 2009

This article has been peer reviewed.

CJEM 2010;12(5):421-30 


\section{INTRODUCTION}

Patient safety has become an important topic in medicine, along with increasing awareness of adverse events. Patient safety has been defined as "freedom from accidental injury" and adverse events as unintended injuries that result from health care management. ${ }^{1}$ Previous population-based research has estimated that $3 \%$ of all adverse events occur in the emergency department (ED). ${ }^{2}$ This may be an underestimate because the focus in the past has been on inpatients, a small fraction of the overall ED population.

In a pilot study of patients discharged from the ED, $6 \%$ had experienced adverse events, the majority (71\%) of which were preventable. ${ }^{3}$ Examples of these adverse events included missed diagnoses, inadequate follow-up plans and suboptimal treatment decisions. If this estimate was accurate, then we could expect 840000 adverse events per year among discharged ED patients in Canada. This statistic is in conflict with prior estimates of the importance of ED care to patient safety. ${ }^{2}$

In the pilot study, patients located in the high-acuity areas of the ED had more adverse events than ambulatory patients. Thus, we chose to study this higher risk population. The goal of this study was to generate an accurate estimate of the risk and type of adverse events and to establish a foundation for planning future interventions for patient safety. We aimed to achieve this by searching for adverse events related to health care received from all providers in the high-acuity areas of the ED.

\section{METHODS}

\section{Study design and setting}

We conducted a prospective cohort study at 2 large tertiary care EDs of The Ottawa Hospital, with a combined census of approximately 112000 patient visits per year. At the time of this study, these centres were staffed by 40 specialty trained emergency physicians (CCFP[EM] and FRCP $[\mathrm{C}])$. This study was approved by the Ottawa Hospital Research Ethics Board.

\section{Inclusion and exclusion criteria}

We included patients older than 18 if they were capable of providing informed consent or had an available substitute decision maker. The patient also had to receive treatment in the resuscitation or observation areas of the ED, and we included admitted as well as discharged patients. In contrast to ambulatory areas, the resuscitation and observation areas represented those patients of highest acuity requiring management on a bed. Acuity was measured by the Canadian Emergency Department Triage and Acuity Scale (CTAS) score. ${ }^{4}$ We planned to include all consecutive patients assessed in the highacuity areas. In the majority of cases these patients had CTAS scores of 1-3 out of 5 and most often arrived by ambulance or were nonambulatory.

We excluded patients if they met any of the following criteria: cognitive impairment due to an organic brain process or major psychiatric illness and no available substitute decision maker; critically ill or in too much distress to be capable of informed consent; unable to complete a telephone interview in English or French (or their substitute decision maker was unable); discharged home and did not have a telephone or otherwise unavailable for follow-up 2 weeks later (as determined at enrolment).

\section{Data collection procedures}

We randomly assigned the research nurse (M.N.) to enrolment shifts to ensure a representative sample of the 24 hours a day, 7 days a week service provided in the ED. This was done using computer-generated random numbers to maintain a ratio of days:evenings:nights:weekends of 2:6:1:1 and then randomized according to campus. At the beginning of each enrolment shift, the research nurse obtained permission from the attending emergency physician to approach each consecutive patient registered to the resuscitation or observation areas of the ED who was alert and capable of providing informed consent. She collected baseline data on all patients who consented in writing to participate in the study. Baseline variables included demographics, presenting complaint, CTAS score, discharge diagnosis and number of patients awaiting inpatient beds at the time of enrolment.

The research nurse was trained to conduct a structured telephone interview in the language of the patient's preference (English or French) at 10-14 days after discharge from the ED. If the patient could not be reached at that time, she conducted the interview as soon as possible after the 14-day planned follow-up date. A trained medical student (J.L.) conducted a chart review of all inpatients by using a structured data collection sheet adapted from the Harvard Medical Practices Study. ${ }^{2} \mathrm{He}$ screened these charts for any flagged outcomes (Box 1) occurring during the first 2 weeks of the admission and 
compiled these into case summaries. The data from these chart reviews were regularly audited by the principal investigator for quality assurance purposes.

We endeavoured to obtain all records of return ED visits or admissions when this occurred at centres other than The Ottawa Hospital. In some cases, this required separate ethics approval from the relevant institution. In the event that a patient could not be reached for followup, we searched the records of The Ottawa Hospital to determine whether that patient may have been admitted to hospital or died.

\section{Outcome measures}

Among those discharged or admitted from the highacuity areas of the ED, we flagged specific outcomes to identify adverse events, the primary outcome of interest. We defined flagged outcomes depending on patient disposition (Box 1). The flagged outcomes for admitted patients were derived from the Harvard Medical Practices Study and have been used in several studies since. ${ }^{2,3,5-13}$ The flagged outcomes for discharged patients were defined in the pilot study using a panel of experts. We excluded any flagged outcomes that were scheduled ED visits or scheduled hospital admissions. Adverse events were defined as flagged outcomes related to ED care (Box 1). Our adverse event definitions were also based on the pilot study. ${ }^{3}$ It is important to note that patients with flagged outcomes that were judged to be due to progression of disease were not classified as adverse events because these outcomes were not related to health care received. For example, a patient returning to the ED with recurring pain from renal colic after appropriate management on the initial visit would be a flagged outcome that was not an adverse event (Box 2).

\section{Outcome assessment}

To identify adverse events, 3 specialty certified attending emergency physicians who worked in the departments being studied were trained in outcome assessment. The outcome assessors (G.H., J.P., C.V.) independently judged the association with provided care by analyzing case summaries using standardized methods adapted from the Harvard Medical Practices Study and replicated in many other patient safety studies including the Canadian Adverse Event Study. $2,3,5-13$ Case summaries consisted of patient demographics, histories of presenting illness, medical histories, findings on physical examination, investigation results and management provided. They also contained a description of the timing, course and response to outcomes. Reviewers were not aware of patient name, sex and treating physician but were aware of outcome as this information was

\section{Box 1. Definitions of flagged outcomes and adverse events}

Flagged outcome: definition depends on the disposition of the patient at the end of the ED visit:

- If discharged, patient experiences any of the following: - new/worsening symptoms

- an unscheduled visit to an ED or health professional

- an unscheduled admission to hospital

- death

- If admitted to hospital, patient experiences any of the following:

- unplanned transfer from another acute care hospital

- unplanned transfer to acute monitoring area and/or neuroobservation area and/or intensive care unit

- unplanned transfer or return to operating room

- organ damage or removal during surgery

- hospital complications

- development of new neurologic deficits during admission

- hospital-acquired infection

- hospital-incurred accident or injury

- adverse drug reaction

- dissatisfaction with care

- litigation

- unplanned readmission to hospital

- unexpected death
Adverse event: a flagged outcome associated with ED management

- Preventable adverse event: an adverse event caused by a health care management problem such as a diagnostic issue, management issue, unsafe disposition decision or suboptimal follow-up

- Diagnostic issue: documented signs, symptoms, laboratory tests or imaging not acted on or an indicated diagnostic test not ordered

- Management issue: suboptimal management plan despite accurate diagnosis or based on an inaccurate diagnosis

- Unsafe disposition decision: patient placed at unnecessary risk of experiencing death or major disability by being sent home

- Suboptimal follow-up: problems with follow-up arrangements led to the development of new symptoms, unnecessary prolongation of symptoms, an unscheduled return visit to the ED or a subsequent unscheduled hospital admission (this could be due to inadequate availability of follow-up appointment, or due to inappropriate follow-up arrangements)

- Medication adverse effect: patient experiences a symptom related to a medication regardless of whether the medication was appropriately prescribed or taken

- Procedural complication: patient experiences adverse consequences of a procedure

$\mathrm{ED}=$ emergency department. 
essential to the determination of adverse events. Reviewers categorized adverse events according to type, severity and preventability. Preventable adverse events were defined as adverse events caused by a health care management problem such as a diagnostic issue, management issue, unsafe disposition decision, suboptimal follow-up, medication adverse effect or procedural complication. These terms are defined in Box 1.

We broke down each flagged outcome assessment into components to guide the reviewer through a structured process when arriving at the conclusion that the outcome was an adverse event. We used a widely used 6-point Likert scale to determine the confidence of the reviewer in health care management causation of the outcome $(1=$ no evidence for management causation, $6=$ certain evidence for management causation). ${ }^{2,3,5-13}$ If 2 out of 3 reviewers had a level of certainty greater than $4 / 6$ (i.e., 5/6 or 6/6), we classified the flagged outcome as an adverse event. To verify these judgments, 2 authors (L.A.C., A.F.) independently reviewed these adverse events and confirmed by consensus which events were related to ED care. This secondary review was blind to the results of the first review by the 3 emergency physicians. We based final determination of an adverse event

Box 2. Examples of adverse events and a flagged outcome not judged to be an adverse event

Adverse events

- Diagnostic issue (preventable): A 55-year-old patient presented with chest pain similar to usual angina. The nurse noted the pain radiated to the patient's back and blood pressure was unequal between arms. ECG and chest radiograph were noted as nil acute and troponin T positive. The patient was referred to cardiology and there was a 7-hour delay in diagnosis of aortic dissection. AE severity: death

- Medication adverse effect (preventable): A 28-year-old patient presented with a 1-week history of confusion. The patient was found to be hyperglycemic, attributed to recent course of steroids. The patient was treated with IV insulin infusion, and 2 serial levels of hypokalemia occurred before treatment initiation. AE severity: required medical intervention

- Management issue (preventable): A 90-year-old patient fell and sustained hip fracture. The patient was admitted for conservative management without deep venous thrombosis prophylaxis. Two weeks later the patient developed pulmonary embolism and responded to heparin treatment. AE severity: required medical intervention

- Procedural complication (not preventable): A 55-year-old patient with known liver cirrhosis presented with shortness of breath and distended abdomen. The patient underwent paracentesis in the ED and returned 2 days later stating that fluid was leaking from paracentesis sites. AE severity: required return ED visit.

- Nosocomial infection (not preventable): A patient presented to the ED with 5 days of bilateral leg weakness followed by sudden onset of paresthesias. Spinal cord compression was diagnosed and a Foley catheter was inserted. Three days later, the patient developed urinary tract infection confirmed by culture. AE severity: required medical intervention.

- Suboptimal follow-up (preventable): A 53-year-old patient with a history of smoking, hypertension and coronary artery disease presented with left-arm paresthesias and weakness. CT head, chest radiography and ECG were all negative. Discharged with neurology follow-up in 2 weeks. On telephone follow-up 2 weeks later the patient stated that the symptoms had worsened and that an appointment had not yet been received. AE severity: symptoms only

- Fall (preventable): A 98-year-old patient was diagnosed with myocardial infarction and congestive heart failure. No documentation of universal fall precautions in place in ED or on ward. The next day the patient fell in the bathroom - no physical injury was documented. The fall was deemed related to poor vision and physical deconditioning. The patient received physiotherapy and occupational therapy treatment. AE severity: required medical intervention

- Unsafe disposition decision (preventable): A 70-year-old patient with a history of chronic obstructive pulmonary disease presented with increasing shortness of breath and fever. The patient was noted to be in moderate respiratory distress. No acute changes on ECG or chest radiograph. The patient was treated and discharged as COPD exacerbation. Returned 8 hours later in severe respiratory distress requiring BiPAP. AE severity: required admission

\section{Flagged outcome not judged to be an adverse event:}

- Progression of disease: A 40-year-old patient had 4 episodes of left flank pain in the past 3 days. CT scan showed ureteric calculus. Patient discharged with Oxycocet and follow-up with urology within the next week. Left flank pain recurred 2 days later and patient presented to the ED.

$\mathrm{AE}=$ adverse event; $\mathrm{BiPAP}=$ bilevel positive airway pressure; $\mathrm{COPD}=$ chronic obstructive pulmonary disease $; \mathrm{CT}=$ computed tomography; $E C G$ = electrocardiogram; $E D$ = emergency department; IV = intravenous. 
on agreement between 4 out of 5 reviewers, a level of agreement that has been previously shown to reduce uncertainty in detection of adverse events. ${ }^{14}$

\section{Calculation of sample size}

The primary outcome was the occurrence of an adverse event. We calculated a sample size of 550 using an estimated rate of adverse events of $6 \%$ based on the pilot study and a bound on the error estimate of $2 \% .^{3}$ Sample sizes for each time stratum were calculated using Scheaffer's formula. ${ }^{15}$

\section{Statistical analysis}

We used descriptive statistics to characterize the population of patients enrolled in the study from highacuity areas of the ED. We calculated the proportion of patients with adverse events including the point and 95\% confidence interval (CI) estimates. We presented the types and severity of adverse events using numerical descriptive statistics. We conducted univariate and multivariate analyses using the $\chi^{2}$ test and stepwise multiple logistic regression, respectively, to determine associations between patient or system factors and adverse events or preventable adverse events. Variables with $p<0.25$ or of great clinical meaning were included in the multiple logistic regression model.

\section{RESULTS}

Patient flow is summarized in Figure 1. We enrolled 518 patients from August to December 2004. Two patients withdrew consent and $13(2.5 \%)$ patients were lost to follow-up; the final number of patients analyzed was 503 .

Table 1 provides the baseline characteristics for all patients who were enrolled and subsequently admitted or discharged. Overall, the patients enrolled in the study had an equal sex distribution (female $n=254,50.5 \%$ ), a median age of 57 years and presented most commonly with chest pain, weakness or abdominal pain.

In terms of system factors (Table 2), most patients were located in resuscitation or observation areas, and most enrolled patients were cared for by one staff emergency physician for the duration of their ED visit. The estimated waiting time represented the head nurse's estimate of how long patients were waiting to be assessed by an emergency physician from their time of registration in the department. The median estimated waiting time was 30 minutes.

Of 107 patients with flagged outcomes, there were 43 patients classified as having had adverse events

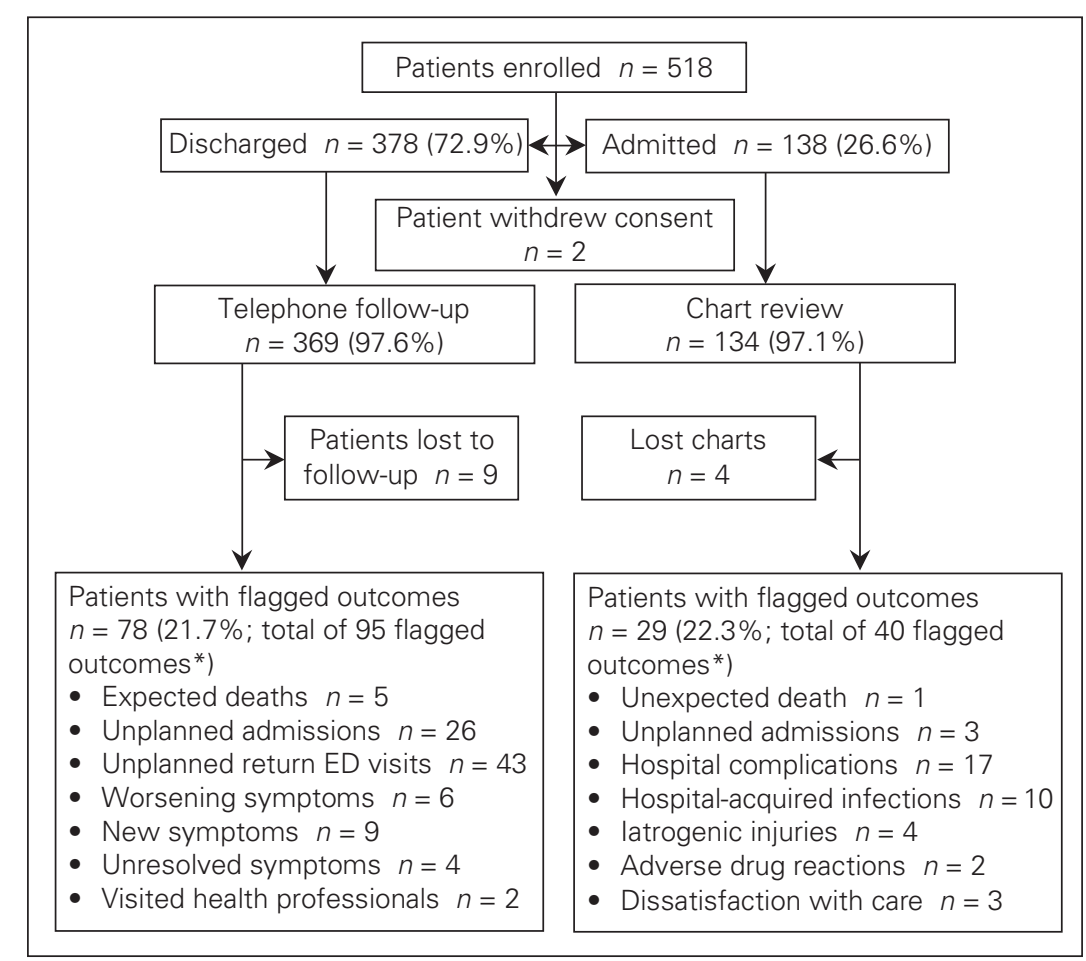

Fig. 1. Flow diagram of patient enrolment and analysis. *Individual patients may have had more than 1 flagged outcome. 
(Table 3), a proportion of $8.5 \%$ (95\% CI $8.1 \%-8.9 \%)$. Of all adverse events identified, 24 (55.8\%) were preventable and $25(58.1 \%)$ were attributable to $\mathrm{ED}$ care. A greater proportion of adverse events were preventable among the discharged population $(n=15,71.4 \%, 95 \%$ CI $51.6 \%-90.4 \%)$ versus the admitted population $(n=$ 9, 40.9\%, 95\% CI 20.4\%-61.5\%). The most common types of adverse events were management issues $(n=18$, $41.9 \%)$, procedural complications $(n=13,30.2 \%)$ and diagnostic issues $(n=10,23.3 \%)$ (Table 3 , see Box 1 for definitions). The adverse event types differed between discharged and admitted populations. In the discharged population, management issues $(n=10,47.6 \%)$, diagnostic issues $(n=7,33.3 \%)$ and unsafe disposition decisions $(n=4,19.0 \%)$ figured most prominently. Admitted patients more commonly had procedural complications ( $n=11,50.0 \%)$, management issues $(n=$ $8,36.4 \%)$ and medication adverse effects $(n=6,27.2 \%)$ or infections $(n=6,27.2 \%)$. Box 2 provides examples of each type of adverse event, preventable adverse events and a flagged outcome not deemed to be an adverse event.
Adverse events were more likely to occur within 1 week of the initial ED visit $(22 / 43,60.5 \%)$. For discharged patients, $52.3 \%$ of adverse events occurred within 7 days and $23.8 \%$ between 7 and 14 days. The same trend held true for admitted patients, with $68.2 \%$ of adverse events occurring within 7 days and $22.7 \%$ between 7 and 14 days.

The most severe adverse event was an unexpected death judged to be related to a delay in diagnosis of aortic dissection (Table 4). One patient suffered permanent disability as a result of a missed inferior wall myocardial infarction. One patient suffered nonpermanent disability in the form of debilitating headaches that persisted perhaps longer than expected because of suboptimal followup. Other adverse events resulted in symptoms only or abnormalities on laboratory testing requiring treatment.

In terms of response to the severity of the adverse event (Table 4), nearly half ( $n=20,46.5 \%)$ of adverse events required some form of intervention. Examples of responses to the severity of adverse events are described in Box 2.

Table 1. Baseline characteristics for patients who received treatment at 2 emergency departments from August to December 2004

\begin{tabular}{|c|c|c|c|c|}
\hline \multirow{2}{*}{$\begin{array}{l}\text { Characteristic } \\
\text { Median (range) age, } † \text { yr }\end{array}$} & \multicolumn{4}{|c|}{ No. (\%) of patients* } \\
\hline & 57 & (18-98) & $\begin{array}{c}\text { Admitted, } n=134 \\
64(19-98)\end{array}$ & $\begin{array}{c}\text { Discharged, } n=369 \\
57(18-94)\end{array}$ \\
\hline \multicolumn{5}{|c|}{ Top 5 presenting complaints } \\
\hline Chest pain & 137 & $(27.2)$ & $29(21.6)$ & $108(29.3)$ \\
\hline Shortness of breath & 44 & (8.7) & $14(10.4)$ & 30 (8.1) \\
\hline Trauma & 30 & (6.0) & 8 (6.0) & $22(6.0)$ \\
\hline \multicolumn{5}{|l|}{ CTAS score } \\
\hline 1 Resuscitation & 5 & $(1.0)$ & $1(0.8)$ & $4(1.1)$ \\
\hline 2 Emergent & 224 & $(44.5)$ & $57(42.5)$ & $167(45.3)$ \\
\hline \multicolumn{5}{|c|}{ Top 5 emergency discharge diagnostic categories } \\
\hline Cardiac & 186 & $(37.0)$ & $39(29.1)$ & 147 (39.8) \\
\hline Gastrointestinal & 73 & $(14.5)$ & $21(15.7)$ & $52(14.1)$ \\
\hline Infection & 40 & (8.0) & $17(12.7)$ & $23 \quad(6.2)$ \\
\hline Neurologic & 35 & (7.0) & $5 \quad(3.7)$ & $30 \quad(8.1)$ \\
\hline Trauma & 28 & (5.6) & $6 \quad(4.5)$ & $22(6.0)$ \\
\hline $\begin{array}{l}\text { CTAS = Canadian Emergency De } \\
\text { *Unless otherwise indicated. } \\
\text { †Age had a slightly skewed distri } \\
\text { †Patient was taking at least } 1 \mathrm{me} \\
\text { \$Patient had medical history of at }\end{array}$ & & & & \\
\hline
\end{tabular}


Our analysis to determine potential patient and system risk factors for adverse events identified no such factors as independently associated with adverse event or preventable adverse event occurrence. Although age was seemingly associated with preventable adverse events in the univariate analysis, none of the patient and system factors had statistically significant odds ratios in the multivariate analysis.

\section{DISCUSSION}

This study is the first prospective multicentre study to evaluate adverse events in high-acuity areas of the ED. We documented an overall proportion of patients with adverse events of $8.5 \%$ with a narrow $95 \%$ CI $(8.1 \%-$ $8.9 \%)$. Over half of these events were preventable (55.8\%) particularly among patients sent home directly from the ED. Overall, we found management issues were the most common type of adverse event. Almost half of the patients required little or no care to manage their adverse event as the severity was minor. The other half, however, required extensive care and 1 patient died as a result of adverse events. Although we found that adverse events were not common in high-acuity ED patients, the preventability and types of adverse events we documented suggest room for improvement in the patient safety of emergency care.

Our proportion of adverse events is higher than those of previous studies of adverse events in EDs. The pilot study of this study found $6 \%$ of discharged ED patients experienced adverse events. ${ }^{3}$ A Taiwanese study performing telephone follow-up of 566 predetermined "high-risk" ED-discharged patients found $4 \%$ of patients who had unscheduled return visits to the ED suffered adverse events. ${ }^{16}$ In a retrospective chart review of deaths in a small community Australian hospital,

\section{Table 2. System characteristics for patient visits to 2 emergency departments from August to December 2004}

\begin{tabular}{|c|c|c|c|}
\hline \multirow[b]{2}{*}{ Characteristic } & \multicolumn{3}{|c|}{ No. $(\%)$ of patients* } \\
\hline & Total, $n=503$ & Admitted, $n=134$ & Discharged, $n=369$ \\
\hline \multicolumn{4}{|l|}{ Patient's location in emergency department } \\
\hline Resuscitation area & $186(37.0)$ & $36(26.9)$ & $150(40.7)$ \\
\hline Observation area & $291(57.9)$ & $81(60.4)$ & $210(56.9)$ \\
\hline Ambulatory areas & $26(5.2)$ & $17(12.7)$ & $9 \quad(2.4)$ \\
\hline \multicolumn{4}{|l|}{ No. of physicians involved in the patient's care } \\
\hline 1 & $459(91.3)$ & $126(94.0)$ & $333(90.2)$ \\
\hline 2 & $38(7.6)$ & 6 (4.5) & 32 (8.7) \\
\hline 3 & $3(0.6)$ & 0 & $3(0.8)$ \\
\hline \multicolumn{4}{|l|}{ No. of patients waiting for beds†‡ } \\
\hline 0 & $98(26.6)$ & - & $98(26.6)$ \\
\hline 1 & $79(21.4)$ & - & $79(21.4)$ \\
\hline 2 & $105(28.5)$ & - & $105(28.5)$ \\
\hline 4 & $27(7.3)$ & - & 27 (7.3) \\
\hline 5 & $26(7.0)$ & - & $26(7.0)$ \\
\hline 6 & $9(2.4)$ & - & $9 \quad(2.4)$ \\
\hline 8 & 12 (3.3) & - & 12 (3.3) \\
\hline \multicolumn{4}{|l|}{ Level of training of primary assessor } \\
\hline Attending staff physician & $245(48.7)$ & $81(60.4)$ & $164(44.4)$ \\
\hline Non-emergency medicine resident & $111(22.1)$ & $12(9.0)$ & 99 (26.8) \\
\hline Emergency medicine resident & $86(17.1)$ & $22(16.4)$ & $64(17.3)$ \\
\hline Medical student & $59(11.7)$ & $18(13.4)$ & $41(11.1)$ \\
\hline \multicolumn{4}{|l|}{ Time of registration } \\
\hline Day (8 am-4 pm) & $243(48.3)$ & $69(51.5)$ & $174(47.2)$ \\
\hline Evening (4 pm-midnight) & $218(43.3)$ & $51(38.1)$ & $167(45.3)$ \\
\hline Night (midnight-8 am) & 42 (8.3) & $14(10.4)$ & 28 (7.6) \\
\hline Median (range) estimated waiting time, $\mathrm{h} \uparrow \S$ & $0.5(0-6)$ & - & $0.5(0-6)$ \\
\hline
\end{tabular}


unplanned return ED visits, ED length of stay of longer than 6 hours or transfer to an acute care facility found an adverse event proportion of $1 \% .{ }^{6}$ Our higher proportion could be due to acuity differences between our study and previous studies, or methodologic differences because our study was prospective, represented the full

\begin{tabular}{|c|c|c|c|}
\hline \multirow[b]{2}{*}{ Outcome } & \multicolumn{3}{|c|}{ No. (\%) of patients } \\
\hline & $\begin{array}{l}\text { Total, } \\
n=503\end{array}$ & $\begin{array}{l}\text { Admitted } \\
n=134\end{array}$ & $\begin{array}{c}\text { Discharged, } \\
n=369\end{array}$ \\
\hline Adverse event* & $43(8.5)$ & $22(16.4)$ & $21(5.7)$ \\
\hline Management issue & 18 & 8 & 10 \\
\hline Procedural complication & 13 & 11 & 2 \\
\hline Diagnostic issue & 10 & 3 & 7 \\
\hline $\begin{array}{l}\text { Medication adverse } \\
\text { effect }\end{array}$ & 9 & 6 & 3 \\
\hline Infection & 6 & 6 & 0 \\
\hline $\begin{array}{l}\text { Unsafe disposition } \\
\text { decision }\end{array}$ & 4 & 0 & 4 \\
\hline Suboptimal follow-up & 2 & 0 & 2 \\
\hline Fall & 3 & 2 & 1 \\
\hline $\begin{array}{l}\text { Preventable adverse } \\
\text { event }\end{array}$ & $24(4.8)$ & $9(6.7)$ & $15(4.1)$ \\
\hline $\begin{array}{l}\text { Adverse event } \\
\text { attributable to ED care }\end{array}$ & $25(5.0)$ & $4(3.0)$ & $21(5.7)$ \\
\hline
\end{tabular}

24 hours of emergency care and used a standardized method of adverse event detection.

Unlike previous inpatient chart review studies designed to detect adverse events, ${ }^{2,5-13}$ to our knowledge, this is the first study to compare admitted and discharged populations in the ED. The different types of adverse events between admitted and discharged populations was an important finding. Previous authors have highlighted diagnostic issues as being the most common contributor to adverse events in the ED. ${ }^{17-19}$ In our study, we found management issues (suboptimal management plans despite accurate diagnosis or based on inaccurate diagnosis) to be the most common. These adverse event types figured most prominently in the discharged population. The differences we uncovered imply a need to tailor specific prevention strategies for the discharged population.

Our approach to this study was grounded in the systems approach to patient safety. ${ }^{20-23}$ This means we took a broad, inclusive view when screening for flagged outcomes to reduce the risk of missing adverse events. We considered flagged outcomes through the first 2 weeks of a patient's admission and for 2 weeks after discharge from the ED. We considered visits to any kind of health care professional as well as changes in symptom patterns. We asked our reviewers to consider the entirety of the patient's health care experience based on the information provided rather than assigning

\begin{tabular}{|c|c|c|c|}
\hline \multirow[b]{2}{*}{ Severity and response } & \multicolumn{3}{|c|}{ No. (\%) of patients } \\
\hline & $\begin{array}{l}\text { Total with } \\
\text { adverse events, } \\
\quad n=43\end{array}$ & $\begin{array}{l}\text { Admitted with } \\
\text { adverse events, } \\
\quad n=22\end{array}$ & $\begin{array}{l}\text { Discharged with } \\
\text { adverse events, } \\
\quad n=21\end{array}$ \\
\hline \multicolumn{4}{|l|}{ Severity* } \\
\hline $\begin{array}{l}\text { Abnormality on laboratory testing } \\
\text { requiring treatment }\end{array}$ & $6(14.0)$ & $6(27.3)$ & 0 \\
\hline$\leq 1$ day of symptoms & $18(41.9)$ & $8(36.4)$ & $10(47.6)$ \\
\hline$>1$ day of symptoms & $16(37.2)$ & $7(31.8)$ & $9(42.9)$ \\
\hline Nonpermanent disability & 1 (2.3) & 0 & 1 (4.8) \\
\hline Permanent disability & $1 \quad(2.3)$ & 0 & 1 (4.8) \\
\hline Death & $1 \quad(2.3)$ & $1 \quad(4.5)$ & 0 \\
\hline \multicolumn{4}{|l|}{ Responset } \\
\hline No treatment (symptoms only) & $10(23.3)$ & $8(36.4)$ & $2 \quad(9.5)$ \\
\hline Required medical/surgical intervention & $20(46.5)$ & 19 (86.4) & $1 \quad(4.8)$ \\
\hline Visit to MD office & $2(4.7)$ & N/A & $2 \quad(9.5)$ \\
\hline ED visit & $4 \quad(9.3)$ & N/A & $4(19.0)$ \\
\hline Admission to hospital & $12(27.9)$ & $\mathrm{N} / \mathrm{A}$ & $12(57.1)$ \\
\hline \multicolumn{4}{|c|}{$\begin{array}{l}\text { ED = emergency department; } \mathrm{MD}=\text { medical doctor; } \mathrm{N} / \mathrm{A}=\text { not applicable. } \\
\text { *If a patient had multiple severity classes only the most severe was counted. } \\
\text { tIf a patient had multiple response classes only the most severe was counted; however, if a patient had multiple adverse events, } \\
\text { all are reported here. }\end{array}$} \\
\hline
\end{tabular}


blame to a single provider. Our goal was to identify issues with our ED as a complex system rather than to diagnose specific errors.

\section{Limitations}

Although we endeavoured to carefully measure adverse events, there are some limitations to our study. First, our analyses were limited by the small number of events. Although this is a concern for establishing the association of baseline factors with outcomes, the sample size was appropriate to address our primary objective of determining the proportion of adverse events among the high-acuity population.

Second, although we minimized "hindsight" bias (tendency of people with outcome knowledge to exaggerate the extent to which they would have predicted an event beforehand) to the best of our ability, it is still possible the severity of patient outcomes influenced ratings. ${ }^{24}$ We mitigated this problem by training our outcome assessors to consider only information that would have been available to the treating emergency physician, asking them to consider other possible competing explanations for the outcome, using a structured rating process and requiring 4 of 5 physicians to agree on the rating. This is a much more vigorous standard than those used for prior ED studies. ${ }^{3,6,16}$

Third, our study was conducted in 2 tertiary care EDs only. We are uncertain of the direction of this potential bias. Despite our effort to enrol consecutive patients on random shifts, it is possible that those patients who were excluded could contribute to a selection bias. Unfortunately, we do not have the data to verify this. We did apply 2 different methods for identifying flagged outcomes among discharged and admitted patients because the standardized screening tool for inpatients was not applicable to discharged patients. To verify whether this influenced the proportion of adverse events, we conducted a sensitivity analysis removing additional outcomes identified from the telephone interview of discharged patients. The number of preventable adverse events among discharged patients remained unchanged (4.1\%). Some of these limitations are inherent to research related to detection of adverse events; however, we endeavoured to minimize their impact as much as possible.

\section{CONCLUSION}

We employed a broad, inclusive and systematic approach to adverse event determination among high-acuity ED patients. This allowed us to detect a higher proportion of adverse events compared with previous inpatient adverse event studies. In particular, the relatively higher proportion of preventable adverse events among the discharged population warrants further investigation among a wider selection of EDs with particular attention to management and diagnostic issues.

Acknowledgement: This study was supported by the Canadian Association of Emergency Physicians and the Department of Emergency Medicine, University of Ottawa.

Competing interests: None declared.

\section{REFERENCES}

1. Kohn LT, Corrigan JM, Donaldson MS. To err is buman: building a safer health system. Washington (DC): Institute of Medicine. National Academy Press; 1999.

2. Brennan TA, Leape LL, Laird NM, et al. Incidence of adverse events and negligence in hospitalized patients: results of the Harvard Medical Practices Study I. N Engl 7 Med 1991;324:370-6.

3. Forster AJ, Rose N, van Walraven C, et al. Adverse events identified following an emergency department visit. Qual Saf Health Care 2007;16:17-22.

4. Bullard MJ, Unger B, Spence J, et al. Revisions to the Canadian Emergency Department Triage and Acuity Scale (CTAS) adult guidelines. CJEM 2008;10:136-42.

5. Baker GR, Norton PG, Flintoft V, et al. The Canadian Adverse Events Study: the incidence of adverse events among hospital patients in Canada. CMAJ 2004;170:1678-86.

6. Wolff AM, Bourke J, Campbell IA, et al. Detecting and reducing hospital adverse events: outcomes of the Wimmera clinical risk management program. Med J Aust 2001;174:621-5.

7. Forster AJ, Clark HD, Menard A, et al. Adverse events among medical patients after discharge from hospital. CMAJ 2004;170:345-9.

8. Forster AJ, Murff HJ, Peterson JF, et al. The incidence and severity of adverse events affecting patients after discharge from the hospital. Ann Intern Med 2003;138:161-7.

9. Forster AJ, Asmis TR, Clark HD, et al. Ottawa hospital patient safety study: incidence and timing of adverse events in patients admitted to a Canadian teaching hospital. CMAJ 2004;170:1235-40.

10. Thomas EJ, Studdert DM, Burstin HR, et al. Incidence and types of adverse events and negligent care in Utah and Colorado. Med Care 2000;38:261-71.

11. Vincent C, Neale G, Woloshynowych M. Adverse events in British hospitals: preliminary retrospective record review. BM7 2001;322:517-9.

12. Wilson RM, Runciman WB, Gibberd RW, et al. The quality in Australian health care study. Med J Aust 1995;163:458-71.

13. Davis P, Lay-Yee R, Briant R, et al. Adverse events in New Zealand public hospitals I: occurrence and impact. N Z Med J 2002;115:U271.

14. Forster AJ, O'Rourke K, Shojania KG, et al. Combining ratings from multiple physician reviewers helped to overcome the uncertainty associated with adverse event classification. J Clin Epidemiol 2007;60:892-901. 
15. Scheaffer RL, Mendenhall W, Ott L. Selecting the sample size and allocating the sample to estimate proportions. Stratified random sampling: elementary survey sampling. North Scituate (MA): Duxbury Press; 1979. p. 78-84.

16. Chern CH, How CK, Wang LM, et al. Decreasing clinically significant adverse events using feedback to emergency physicians of telephone follow-up outcomes. Ann Emerg Med 2005; 45:15-23.

17. Kachalia A, Gandhi TK, Puopolo AL, et al. Missed and delayed diagnoses in the emergency department: a study of closed malpractice claims from 4 liability insurers. Ann Emerg Med 2007;49:196-205.

18. Croskerry P, Sinclair D. Emergency medicine: A practice prone to error? CJEM 2001;3:271-6.

19. Famularo G, Salvini P, Terranova A, et al. Clinical errors in emergency medicine: experience at the emergency department of an Italian teaching hospital. Acad Emerg Med 2000;7: 1278-81.
20. Reason J. Human error: models and management. $B M J$ 2000;320:768-70.

21. Reason J. Understanding adverse events: the human factor. In: Vincent C, editor. Clinical risk management. London (UK): BMJ Books; 2001. p. 9-30.

22. Adams JG, Bohan JS. System contributions to error. Acad Emerg Med 2000;7:1189-93.

23. Callahan CD. The systems approach to error reduction in the emergency department. Emergency Medicine Specialty Reports 2004;S04180:1-8.

24. Henriksen K, Kaplan H. Hindsight bias, outcome knowledge and adaptive learning. Qual Saf Health Care 2003;12(Suppl 2): ii1146-50.

Correspondence to: Dr. Lisa Calder, The Ottawa Hospital, Civic Campus, Rm. F654, 1053 Carling Ave., Ottawa ON K1Y 4E9; lcalder @ohri.ca

\section{LOOKING FOR A NEW JOB?}

In print and online, the best way to advertise or find employment opportunities in academic, administrative or community emergency medicine is through the Canadian Journal of Emergency Medicine.

Print version of CJEM: The deadline for advertising in the print version of CJEM is one month before issue date. For ad rates and further information, please contact Journal Advertising (800 663-7336 or 613 731-8610; advertising@cma.ca).

\section{LOOKING FOR AN EMERG DOc?}

SPECIAL BONUS: As a bonus to print advertisers, $C J E M$ is pleased to offer website advertising space on CAEP's website (www.caep.ca) free of charge.

CAEP website alone: Advertising in the CAEP website alone is billed at a rate of $\$ 100$ a month, and can be obtained at any time. Please contact CAEP's Head Office for advertising solely on the website (800 463-1158 or advertising@caep.ca).

\section{À LA RECHERCHE D'UN NOUVEL EMPLOI?}

En version imprimée et en ligne, la meilleure façon de placer une annonce ou de trouver un emploi en médecine d'urgence dans un contexte universitaire, administratif ou communautaire est par le biais du Journal canadien de la médecine d'urgence.

Version imprimée du $\mathcal{J C M U}$ : la date butoir pour placer une annonce dans la version imprimée du 7CMU est un mois avant la date de parution de la revue. Annonces publicitaires (800 663-7336 ou 613 731-8610; advertising@cma.ca).

\section{À LA RECHERCHE D'UN MÉDECIN D'URGENCE?}

PRIME SPÉCIALE : Les médecins qui placeront une annonce dans la version imprimée du JCMU recevront sans frais un espace pour leur annonce sur le site web de l'ACMU (www.caep.ca).

Site web de l'ACMU seulement : Pour placer une annonce sur le site web de l'ACMU seulement, le coût est de 100 \$ par mois et l'annonce peut être placée en tout temps. Veuillez communiquer avec le siège social de l'ACMU pour les annonces sur le site web seulement (800 463-1158 ou advertising@caep.ca). 